slance between the portal and the efferent vein consisting in the fact that each vein intervenes between two sets of capillary vessels. And thus we find that as an impediment to the circulation throuch the liver causes a serous exudation into the cavity of the peritoneum from the capillary vessels in which the portal vein takes its rise, so an impeded circulation through the kidney causes a serous exudation from the capillary vessels in which these miniature portal veins-the efferent veins-originate, and this serous exudation from the Malpighian capillaries passes into the uriniferous tubes. Dr. George Robinson, Frerichs, and others have shown that a ligature on the renal vein of a rabbit causes a retrograde engorgement of the Malpighian capillaries, and a consequent escape of blood constituents in to the uriniferous tubes, which, mingling with the urine, render it albuminous. In cases of Bright's disease there is an impeded circulation through the intertubular capillaries, which is, in part at least, occasioned by the pressure of the swollen tubes upon the vessels which lie between them; there is, consequently, an engorgement of the Malpighian capillaries, a serous exudation into the uriniferous tubes, and thus an albuminous condition of the urine.

We see, then, that while an impeded circulation throngh the lungs throws back the blood upon the bronchial reins and capillaries, and causes a serous, mucous, or sanguineous exudation into the bronchial tubes, an impeded circulation through the liver distends the portal veins and capillaries, and causes hæmorrhage from the mucous membrane of the alimentary canal, or serous effusion into the cavity of the peritoneum; and, lastly, an impeded circulation through the kidney distends the Malpighian capillaries, and causes a serous exudation, and sometimes hæmorrhage, into the uriniferous tubes. The results in each case are readily explaincd by a reference to the peculiarities of the circulation in each of these important organs-the lung, the liver, and the kidney. Without such a reference the facts are utterly unintelligible.

If there be anyone who doubts whether the retrograde action of a block to the circulation can be so far-reaching as I have described it to be, he has only to be reminded of the undoubted fact that an obstructive valvular disease on the left side of the heart may affect the most remote parts of the circulatory system. Thus the impediment resulting from a defective mitral valve may extend backwards through the pulmonary capillaries to the systemic veins and capillaries, causing anasarea of the feet, \&c.; it may extend through the capillaries within the liver to the portal vein and its capillary origin, causing ascites; and through the intertubular renal capillaries to the Malpighian capillaries, causing albuminuria. It is manifest that neither extreme distance from the seat of obstruction, nor the intervention of two successive sets of apillaries, will prevent that retrograde passive engorgement of

\section{ON CERTAIN MODIFICATIONS OF MAREY'S SPHYGMOGRAPH.}

\author{
By FRANCIS E. ANSTIE, M.D.
}

SeVERAL very important changes in certain details of Marey's sphygmograph have been made since its introduction into this country, and it is desirable that the profession should understand clearly the principles on which they have been adopted, for the discovery of these principles has given an altogether new aspect to sphygmography. Ingenious and beautifully manufactured as the original French instrument was, it possessed certain faults which rendered its employment by anyone, except an adept, worse than useless, so many were the fallacies to which its indications might lead when it was applied in an improper manner. The alterations which have now been made, although they do not render the instrument absolutely perfect, do at least remove a great many difficulties from its general use, by making it much more easy of application in such a way as to get uniform results.

The first important improvement was made in 1866 by $\mathrm{Mr}$. Berkeley Hill. The few persons who were working the instrument in England had felt, above all things, the annoyance which was produced by the clumsy method of adjustment. Nothing was more common than for five or ten minutes, or a quarter of an hour, to be lost in securing a tracing which represented the full power of the pulse, and it not very unfrequently happened that no tracing could be obtained at all. Mr. Hill perceived that it was necessary that there should be a uniform position of the hand and arm, that the limb should be solidly maintained in that position, and that the fastenings should be of such a character that when once the tactile spring had been so placed on the artery as to receive its fullest pulsations, there need be no more adjustment, but the tracings might be taken immediately. The reader will observe, in reference to Fig. 1, that these purposes are admirably secured by the pad on which the arm rests, and the elastic bands by which the sphygmograph is held in place. The hand is bent back over the thick end of the cushion, and fastened by an elastic strap across the palm, which should always be drawn tight enough to make the knuckles touch the table or bed. The radial artery is thus projected to the utmost, and the application of the instrument is in every way facilitated, as well as made more accurate and certain.

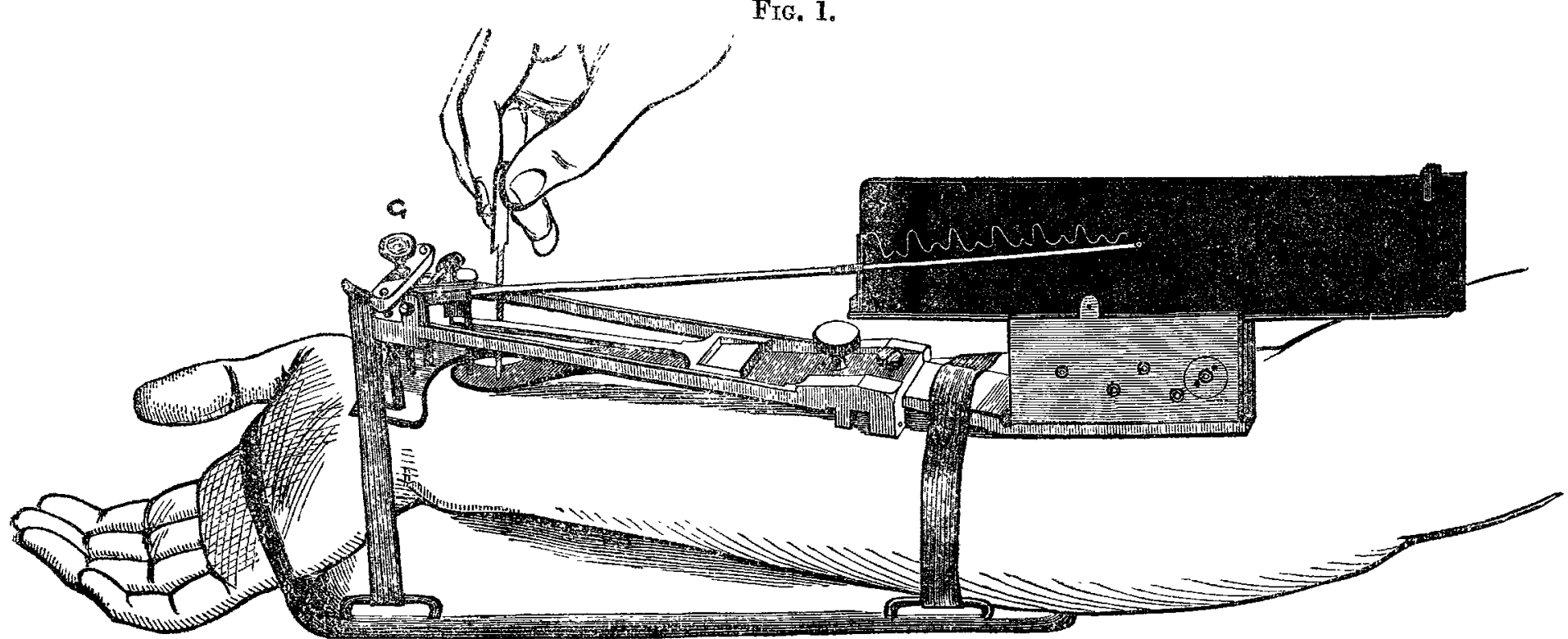

vessels which results from a block in the course of the circulating current.

In a future communication I shall endeavour to show that a careful study of the hydraulics of the circulation will lead us to the establishment of some simple, yet most useful, guiding principles for the employment of bloodletting, general and local, and for the use of hot and cold applications and counterirritants in the treatment of inflammation.

Savile-row, June, 1868.
Even more important is the new apparatus made by Messrs. Weiss, and a similar arrangement thy Mr. Meyer, for the graduation of the pressure of the tactile spring upon the artery. It is not too much to say that this improve nent, the principle of which originated with Dr. Burdon-Sanderson, has put an entirely new value upon the sphygmograph, increasing indefinitely the precision of its record. I must ask the reader to follow me carefully in my explanation of the matter, becanse it is evident, from the remarlas which I frequently 
hear made, that the new arrangement is much misunderstood.

The first commencement of the new mode of modifying pressure was owing to the observation by Dr. Sanderson, that certain fever puises were too weak to be effectively recorded unless the spring of the sphygmograph were weakened by extending it at its free end. This was at first accomplished by putting pledgets of lint, next by putting blocks, of various thickness, under the brasswork of the instrument at the end towards the wrist. By these means the instrument was pushed away from the artery, and the free end of the spring had to be extended (by turning its little screw) in order to bring it in contact with the radial. Dr. Sanderson then reconsidered the whole principle of spring pressure; and he arrived at the conclusion that the large button in the centre of the instrument, which was devised by Marey for the purpose of altering pressure, cannot conveniently be so used as to modulate pressure in uniform gradation, even for high pressures, while for the weaker pulses it does not provide the means of sufficiently weakening the spring. He adopted the principle of fixing the centre button at a definite pressure of 300 grammes, which it was supposed would be enough for the most resistent pulses; and when this required to be diminished, it was done by putting blocks of different thicknesses under the wrist end of the sphygmograph (screwing down the free end of the spring in corresponding degree). The distance between the tactile spring and the writing lever, having been measured (in tenths of an inch) when the 300 grammes pressure was on, was remeasured after the free end of the spring had been extended sufficiently to develop the maximum pulse. The proportion between the two distances showed the amount to which the pressure has been lowered-e.g., if at 300 grammes, the distance was $\frac{5}{10}$ of an inch ; then an increase of the distance to one inch would mean a reduction of pressure to 150 grammes; and so on.

Dr. Sanderson's principle being established, it only remained to make its mechanical application easy. This has been done at my instance by Mr. Foveaux, of Messrs. Weiss and Son's, and at Dr. Sanderson's instance by Mr. Meyer. Instead of the graduated blocks, which were inconvenient and wanting in precision, an apparatus is used for regulating the extension of the free end of the spring, which is represented in the woodcuts as G. [In the larger drawing, Fig. 1 , and in Fig. 2 which represents the end view, Weiss's modification is shown ; in Fig. 3, an end view, Meyer's modification. The difference is only in the most trifling details.] By turning the screw at $\mathrm{G}$, after

FIG. 2.

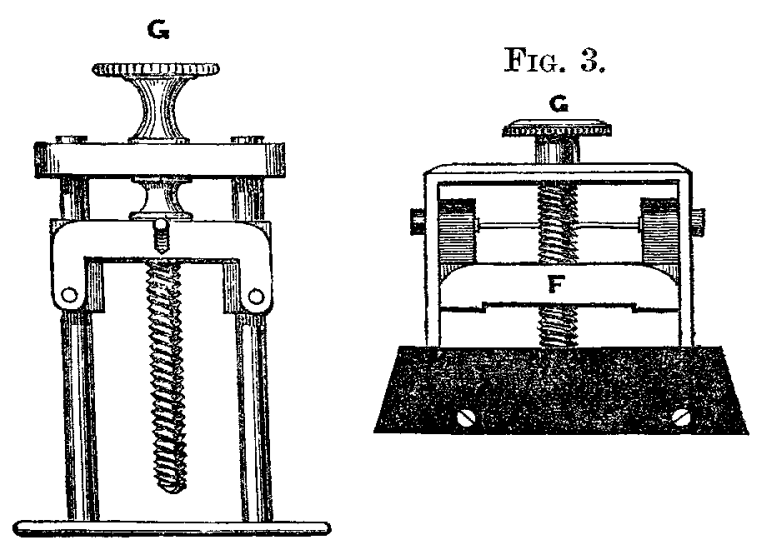

the instrument is fastened on the arm at 300 grammes pressure, ${ }^{*}$ the sphygmograph can be separated from the artery exactly to such a distance as shall ensure that when the free end of the spring is screwed down so as again to rest on the artery, the maximum pulse-curve will be secured. By measuring the distance between the tactile spring and the horizontal brass rod immediately above it (vide Fig. 1), before and after the reduction of the pressure, one obtains two numbers, the proportion of which to each other shows the strength of pressure which produces a maximum pulse-curve. The measuring instrument is simply a little piece of boxwood, of about an inch and a half in length, graduated in tenths of an inch, and set in a little wooden handle. Further, at my suggestion, Messrs. Weiss have added a scale which (under certain conditions) shortens the process of measuring the pressure. One of the pillars of the little graduation apparatus is marked in tenth

* Since this was originally written, Dr. Sanderson has come to the conclusion that 400 grammes is the best maximum at which to fix the centre screw, as it appears there are a few pulses for which $300 \mathrm{grammes}$ is not enough pressure. of an inch. When the sphygmograph is applied repeatedly to the same person, it is possible to make this scale serve instead of the wooden measure, after the latter has been once used. For example, supposing that on the first occasion of taking the pulse of a fever patient I find that the distance between the tactile spring and the horizontal brass rod must be increased from ${ }_{1}^{3}$ to $\frac{B}{10}$ inch in order to get the maximum pulse-curve. That means that the pressure is reduced to 150 grammes. [During these experiments the position of the hand must be invariable, the knuckles touching the table or bed, and the end of the tactile spring resting on a selected point of the artery, which should be marked and never varied.] Looking now at the scale on the brasswork, I see that the pillars of the graduation apparatus have shifted their position by so many tenths of an inch. Hereafter I know that, in the same position of hand and arm, so much alteration of the scale in the brasswork means, in this patient, so much alteration of spring pressure, and can thus read off the resisting power of the pulse on successive days in a comparatively simple manner.

The value of being able to mathematically estimate the resisting power of a pulse, which we owe in the first instance to Dr. Sanderson, is very great. The practical purposes to which it may be turned are very numerous, but I shall content myself with one which will not fail to impress the reader. If, on examining a patient with acute febrile symptoms (no matter from what cause), $I$ find that the pressure which is best suited for bringing out the maximum pulse-curve is very low (say 100 to 120 grammes), I am pretty certain that the case will require wine. If, on the other hand, I discover that the pulse requires 200 grammes power to elicit its maximum trace, then the case does not, at any rate as yet, require stimulation.

Another item of improvement which has been made is the abolition of the check spring which used to guard the ascent of the writing lever. This has been proved to be always useless, and sometimes mischievous, as causing fallacious traces.

Finally, an important source of trouble in application, and of fallacy in result, has been removed by the substitution of smoked glasses scratched by a needle-point, for the old pen, ink, and paper of the writing apparatus. Glass slides are used, blackened with the smoke of paraffine; and the writing lever is armed with a needle-point. Friction is thus reduced to a minimum, and the resulting traces are delicate and beantiful. They may be preserved by varnishing the slide with photographic varnish.

Wimpole-street, June, 1868.

\section{A Aflitrot}

OF THE PRACTICE OF

\section{MEDICINE AND SURGERY IN THE}

\section{HOSPITALS OF LONDON.}

Nulla autem est alia pro certo noscendi via, nisi quamplurimas et morborum

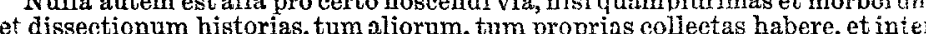
se comparare.-MorgaGNI De Sed. et Caus. Morb., lib. iv. Proømium.

\section{WESTMINSTER HOSPITAL.}

TWO CASES IN WHICH FLEXIBLE BOUGIES WERE BROILY IN THE URETHRA AND BLADDER DURING THE TREATMENT OF STRICTURE OF THE URETHRA.

(Under the care of Mr. BARNARD HoLT.)

Is reference to the following cases, Mr. Holt remarked that similar ones were not at all uncommon; the same results had been frequently recorded where it had been necessary to resort to one or other kind of operation for the extraction of fragments of elastic catheters or bougies which were broken either in the urethra or bladder. He deprecated the use of such instruments, not only because of their danger, but because they were much less effective, gave more pain, and were passed with much greater difficulty than the highly polished solid bougie. All his patients who had been subjected to the operation by rupture were taught to pass solid bougies-an evidence of the facility with which the proceeding could be 